\title{
Effect of Pathogen Aggressiveness and Vinclozolin on Efficacy of Rhodotorula glutinis PM4 Against Botrytis cinerea on Geranium Leaf Disks and Seedlings
}

\author{
J. W. Buck, Department of Plant Pathology, University of Georgia, Georgia Station, Griffin 30223; and S. N. Jeffers, \\ Department of Entomology, Soils, and Plant Sciences, Clemson University, Clemson, SC 29634
}

\begin{abstract}
Buck, J. W., and Jeffers, S. N. 2004. Effect of pathogen aggressiveness and vinclozolin on efficacy of Rhodotorula glutinis PM4 against Botrytis cinerea on geranium leaf disks and seedlings. Plant Dis. 88:1262-1268.

Efficacy of the yeast Rhodotorula glutinis isolate PM4 as a biological control agent against 29 isolates of Botrytis cinerea obtained from greenhouse-grown ornamentals was assessed in vitro on geranium leaf disks. Isolates of $B$. cinerea varied in aggressiveness in the absence of either biological or chemical controls; diameters of lesions produced on leaf disks ranged from 0.8 to $12.3 \mathrm{~mm}$. Efficacy of $R$. glutinis PM4 against the different isolates of $B$. cinerea varied greatly; lesion diameters ranged from 0.2 to $10.3 \mathrm{~mm}$ when the yeast was present. The yeast significantly reduced lesion development by $16 \mathrm{~B}$. cinerea isolates in each of two replicate trials and by 9 isolates in one of the trials; however, 3 isolates were not inhibited by the yeast on geranium leaf disks. The yeast significantly reduced lesion development by $B$. cinerea isolate 01 , used as a standard for comparison, in four of six trials. Fourteen of the $B$. cinerea isolates were inoculated onto geranium seedlings and produced a range of lesion sizes (2.9 to $16.4 \mathrm{~mm}$ ), similar to that produced on leaf disks. Efficacy of the yeast in combination with a reduced rate $(0.1 \times)$ of the fungicide vinclozolin $\left(50 \mu \mathrm{g}\right.$ of active ingredient $\left.\mathrm{ml}^{-1}\right)$ was evaluated on geranium seedlings against 10 isolates of $B$. cinerea that were resistant to vinclozolin. Addition of vinclozolin to the yeast significantly reduced lesion diameter by five of the isolates compared with diameters of lesions produced in the presence of the yeast alone. Lesions produced by nine of the resistant isolates were $2.6 \mathrm{~mm}$ or smaller in both trials on plants treated with the mixture of yeast and vinclozolin. The effect of vinclozolin concentration $\left(0\right.$ to $500 \mu \mathrm{g}$ a.i. $\left.\mathrm{ml}^{-1}\right)$ on biocontrol efficacy of $R$. glutinis PM4 was evaluated using three resistant isolates of $B$. cinerea and geranium seedlings. Disease control was significantly better at higher concentrations of fungicide for two of the isolates. Linear regression of lesion diameter against vinclozolin concentration showed a significant effect on yeast biocontrol efficacy with $B$. cinerea isolate FL-2-b $\left(y=6.20-0.63 x ; r^{2}\right.$ $=0.74)$ and isolate BR-1 $\left(y=4.10-0.32 x ; r^{2}=0.28\right)$ but there was no significant effect with isolate GG-2-b. Overall, PM4 exhibited biocontrol activity on both geranium leaf disks and seedlings against a number of isolates of $B$. cinerea that varied in aggressiveness. Variability in biocontrol efficacy against isolates resistant to vinclozolin usually was reduced by the addition of vinclozolin.
\end{abstract}

Botrytis blight is a very common and economically important disease that affects many greenhouse-grown ornamental crops (e.g., poinsettia, cyclamen, and geranium), and Botrytis cinerea, the causal agent, can infect all aerial plant organs (i.e., stems, leaves, and flowers) (7). Conidia can serve as a primary source of inoculum and are presumed to be ubiquitous and genetically heterogeneous in greenhouses (21). B. cinerea is a candidate for biological control because the conidia of many isolates are nutrient-dependent $(15,16)$ and compe-

Corresponding author: J. W. Buck

E-mail: jbuck@griffin.uga.edu

This work was funded by grants from the Floriculture Industry Research and Scholarship Trust (FIRST) and The Gloeckner Foundation, Inc.

Accepted for publication 5 July 2004.

Publication no. D-2004-0907-01R

(C) 2004 The American Phytopathological Society tition for nutrients is presumed to be one of the major mechanisms of antagonism by biocontrol yeasts $(12,13,16,20)$. Biological control of $B$. cinerea by yeasts has been observed on greenhouse-grown vegetables $(8,13)$ and on fruit in postharvest systems $(14,16,18)$. Epiphytic yeasts isolated from turfgrass and ornamental plants exhibited biocontrol activity against $B$. cinerea on geranium in both leaf disk (2) and seedling assays (3). In fact, under nutrient-limiting conditions, many phylloplane yeasts have the potential to antagonize $B$. cinerea (2).

Two obstacles impeding the use of biological control in commercial agriculture are a lack of both consistent efficacy and a level of control comparable to that achieved with chemical fungicides (11). Few studies are available on the effect of variability among $B$. cinerea isolates on efficacy of biocontrol yeasts. In studies on postharvest diseases of fruit, the addition of calcium salts (26), salicylic acid (22), or low rates (i.e., $10 \%$ or less) of fungicides $(9,10)$ improved efficacy of biocontrol yeasts. The addition of fungicides to biocontrol yeasts also reduced the variability in disease control obtained by the yeasts alone in some studies $(1,4,5,9,10,23)$. However, in most cases, the target pathogens were sensitive to the fungicide being tested. In a previous study, the senior author evaluated the effects of 10 different fungicides on the biocontrol efficacy of several phylloplane yeasts, including Rhodotorula glutinis PM4, against one isolate of $B$. cinerea on geranium seedlings (3). Three fungicides (azoxystrobin at $1 \times$ and $0.1 \times$, trifloxystrobin at $1 \times$ and $0.1 \times$, and vinclozolin at $1 \times$ and $0.5 \times$ of label rates) provided highly effective and consistent disease control when used in combination with $R$. glutinis PM4, whereas thiophanate-methyl negatively affected yeast biocontrol efficacy. Increased disease control by a yeast-vinclozolin mixture was observed for eight other isolates of $R$. glutinis, two isolates of $R$. graminis, and two isolates of $R$. mucilaginosa. The improved efficacy by the combination of vinclozolin with a yeast was unexpected because the isolate of $B$. cinerea was not sensitive to the fungicide (3). Additional research is needed to determine whether vinclozolin will enhance biocontrol efficacy of $R$. glutinis PM4 against other isolates of $B$. cinerea resistant and sensitive to vinclozolin.

In a previous study, biocontrol activity of 25 yeasts against a single isolate of $B$. cinerea under nutrient-limiting conditions on geranium leaf disks was highly variable among yeast isolates within a trial and between trials with the same isolates (2). Increasing the concentration of yeast relative to that of $B$. cinerea conidia from 10:1 to 100:1 improved biocontrol efficacy and reduced variability. Therefore, it was concluded that, under the conditions used in the study, many phylloplane yeasts had the potential to antagonize $B$. cinerea (2). However, there is much genetic and phenotypic variability among isolates of $B$. cinerea $(21,27,28)$ that presumably could limit the efficacy of yeasts used as a biocontrol agent in a commercial setting. For example, the effect of pathogen aggressiveness on yeast biocontrol efficacy has not been studied. Therefore, the objectives of this study were threefold: to determine the biocontrol efficacy of the yeast $R$. glutinis PM4 under nutrient-limiting conditions against a diverse population of isolates of $B$. cinerea obtained from greenhouse-grown ornamental plants, to com- 
pare results of biocontrol efficacy using geranium leaf disks and seedlings, and to further evaluate the beneficial effects of vinclozolin on yeast biocontrol efficacy.

\section{MATERIALS AND METHODS}

Pathogen and yeast cultures. Twentyeight isolates of $B$. cinerea recovered from various ornamental plants in South Carolina with known sensitivities to vinclozolin and thiophanate-methyl (27) were used in this study. An additional isolate of $B$. cinerea (Bot 01) used in previous yeast biocontrol studies $(2,3)$ was included as a standard for comparison. All isolates were stored as conidium suspensions in $15 \%$ glycerol at $-70^{\circ} \mathrm{C}$. Working cultures were started on potato dextrose agar (PDA; Becton, Dickinson, and Co., Franklin Lakes, NJ) and incubated below two 34-W coolwhite fluorescent light bulbs (photoperiod $=8 \mathrm{~h}$ of day and $16 \mathrm{~h}$ of dark; light intensity was approximately $50 \mu \mathrm{mol} \mathrm{s} \mathrm{m}^{-1}$ ) for 2 to 3 weeks at 22 to $24^{\circ} \mathrm{C}$. To prepare conidium suspensions for experiments, cultures were flooded with $10 \mathrm{ml}$ of sterile $0.05 \%$ Tween 20 (J. T. Baker, Phillipsburg, $\mathrm{NJ}$ ), conidia were dislodged with a glass rod, and suspensions were passed through five layers of sterile cheesecloth to remove hyphal fragments. Conidia were pelleted by centrifugation (approximately 1,500 $\times$ $g$ ), resuspended in sterile distilled water, and enumerated using a hemacytometer. Suspensions then were diluted with sterile, distilled water to produce a final working spore density of $1 \times 10^{5}$ conidia ml ${ }^{-1}$.

The biocontrol yeast $R$. glutinis PM4 (2) was stored as a cell suspension in $15 \%$ glycerol at $-70^{\circ} \mathrm{C}$. Working cultures were produced by streaking frozen cells on PDA and then incubating cultures at $25^{\circ} \mathrm{C}$ in the dark for 3 days. To produce cell suspensions for experiments, a loopful of yeast cells was suspended in distilled water, and the concentration was enumerated with a hemacytometer; suspensions were diluted with sterile, distilled water to a final working cell density of $1 \times 10^{6}$ cells ml ${ }^{-1}$.

Leaf disk assay. A leaf disk assay was used to evaluate biocontrol efficacy of yeast isolate $R$. glutinis PM4 against isolates of $B$. cinerea. Geranium (Pelargonium $\times$ hortorum $\mathrm{cv}$. White Elite) stock plants were grown from seed in Metro-Mix 360 (The Scotts Co., Marysville, OH) in 11-liter pots and fertilized every 2 weeks with Peters 15-15-15 Geranium Special (The Scotts Co.). Approximately 12-weekold leaves were removed and surface disinfested by immersion first in $0.53 \% \mathrm{NaOCl}$ for $60 \mathrm{~s}$ and then in $70 \%$ ethanol for $20 \mathrm{~s}$; leaves then were rinsed three times in distilled water (2). Leaf disks (12 $\mathrm{mm}$ in diameter) were cut and placed on sterilized filter paper moistened with sterile water in 90-mm-diameter glass petri dishes. All isolates of $B$. cinerea were tested alone and with R. glutinis PM4 on the leaf disks. A ratio of 10:1 was used in all treatments where both $B$. cinerea and $R$. glutinis PM4 were used (i.e., $1 \times 10^{6}$ yeast cells $\mathrm{ml}^{-1}$ and $1 \times 10^{5}$ conidia $\mathrm{ml}^{-1}$ ). Inocula were prepared in $25 \mathrm{mM}$ glucose and 20 -fold dilute yeast nitrogen base (Becton, Dickinson, and Co.; 2,3). Each of 15 disks in a dish was inoculated with a single $25-\mu$ drop of test suspension, dishes were placed at $21^{\circ} \mathrm{C}$ below two cool white fluorescent light bulbs ( $8 \mathrm{~h}$ of day and $16 \mathrm{~h}$ of dark) for $72 \mathrm{~h}$, and then lesion diameters $(\mathrm{mm})$ were measured. Three replicate dishes (15 disks per dish) were used for each treatment. The average lesion diameter for each dish was calculated to determine the replicate value, and then the mean of the three replicates were calculated. The 28 isolates were tested in three independent experiments, with Bot 01 included in all three experiments as a standard for comparison, and each experiment was conducted at least twice. Therefore, the biocontrol efficacy of $R$. glutinis PM4 was tested at least twice against each isolate of $B$. cinerea using the leaf disk assay.

Seedling assay. Six isolates of $B$. cinerea were selected based on results from the leaf disk assay and tested further on geranium seedlings to determine if the two assays produced comparable results. The isolates selected produced lesions $>8.5 \mathrm{~mm}$ (more aggressive; BT-3-b, B-9-a, and DD$8-a)$ or $<6.0 \mathrm{~mm}$ (less aggressive; GO-2-b, UG-2, and S-1-a) on geranium leaf disks in at least one trial (Table 1). White Elite geranium seed were sown in Sunshine GBX general purpose potting mix (Sun Gro Horticulture Inc., Bellevue, WA) in 72-cell plug flats $(5.7$ by 4.0 by $2.5 \mathrm{~cm}$; TLC Polyform, Inc., Plymouth, MN). Flats were placed on a greenhouse bench under ambient light with average day and night temperatures of 26 and $20^{\circ} \mathrm{C}$, respectively, until seedlings had fully expanded cotyledons (approximately 12 to 14 days). Each 72-cell flat was separated into 12 six-cell sections with a single seedling in each cell. Both cotyledons of each seedling were inoculated with a single $10-\mu \mathrm{l}$ drop of test suspension. Treatments included each isolate of $B$. cinerea alone or in combination with $R$. glutinis PM4 in $25 \mathrm{mM}$ glucose and 20-fold dilute yeast nitrogen base. Three six-seedling replicates were used for each treatment, and each replicate of a treatment was placed in a separate plastic container (59 by 43 by $15 \mathrm{~cm}$; Sterlite Corp., Townsend, MA) with a sealed lid. Approximately 1 liter of tap water was added to each container to maintain relative humidity above $95 \%$. Relative humidity in the containers was monitored using Watchdog data loggers (Model 150; Spectrum Technologies Inc., Plainfield, IL). Sealed containers with inoculated seedlings were placed in the dark at $21^{\circ} \mathrm{C}$ for $72 \mathrm{~h}$, and then lesion diameters $(\mathrm{mm})$ were measured on both cotyledons of each seedling in a replicate (i.e., 12 cotyledons/replicate). Datum for each replicate was the average of all 12 cotyledons. Each isolate of $B$. cinerea was tested three times.

Effect of vinclozolin on yeast biocontrol efficacy. Ten isolates of $B$. cinerea previously determined to be resistant to vinclozolin (BR-1, BT-3-b, CC-1-a, CH-6b, CN-2-b, FL-2-b, GG-2-b, H-3-a, S-1-a, and UG-1) (27) were used to test the effect of vinclozolin on yeast biocontrol efficacy. Each isolate was inoculated onto geranium cotyledons alone or in combination with yeast, with vinclozolin, or with vinclozolin and yeast. Vinclozolin (Touché $50 \mathrm{EG}$, $50 \%$ a.i.; Lesco Inc., Strongsville, $\mathrm{OH}$ ) was suspended in sterile distilled water, agitated, and added at a final concentration of $50 \mu \mathrm{g}$ a.i. $\mathrm{ml}^{-1}$ (3), just under $0.1 \times$ the label rate of $600 \mathrm{mg} \mathrm{l}^{-1}$. White Elite geranium seedlings were produced as stated previously. Again, three six-seedling replicates were used for each treatment, and each replicate of a treatment was placed in a separate plastic container with a sealed lid. Data were collected as in the seedling assay. The experiment was repeated.

Of the 10 vinclozolin-resistant isolates, three (FL-2-b, BR-1, and GG-2-b) were tested further on seedlings to determine if there was an interaction between fungicide concentration and yeast biocontrol efficacy. Each isolate was inoculated alone and with yeast in four concentrations of vinclozolin $\left(0,5,50\right.$, and $500 \mu \mathrm{g}$ a.i. $\left.\mathrm{ml}^{-1}\right)$ using an experimental design similar to the one used above, and the experiment was repeated.

Statistical analysis. Data for each trial of an experiment were analyzed independently by two-way analysis of variance (ANOVA) with isolates of $B$. cinerea and yeast (with or without) as main effects. If the isolate-yeast interaction was not significant $(P>0.05)$, means of treatment main effects were separated by Fisher's least significant difference (LSD) with $P=$ 0.05 . If the interaction was significant, data for each trial were analyzed by one-way ANOVA, and means for individual isolateyeast treatments were separated by LSD $(P$ $=0.05)$. All ANOVAs were conducted using the general linear models procedure (PROC GLM) of SAS (SAS Institute Inc., Cary, NC). Data from the vinclozolin concentration experiments were analyzed by regressing lesion diameter on $\log _{10}$ (vinclozolin concentration) for each isolate of B. cinerea.

\section{RESULTS}

In all experiments, except the vinclozolin concentration experiments, there was a significant trial-treatment interaction, indicating that results between or among trials were not consistent. Therefore, data for individual trials were analyzed independently for these experiments. In twoway ANOVAs of individual trials for each experiment, there was a significant interaction between main effects (i.e., isolatesyeast treatment). Therefore, one-way ANOVAs were used to compare the simple 
effects of individual isolate-yeast treatments.

Leaf disk assay. A wide range in lesion diameters ( 0.8 to $12.3 \mathrm{~mm}$ ) was observed among the 28 isolates of $B$. cinerea inoculated onto geranium leaf disks without yeast -2.0 to $11.9 \mathrm{~mm}$ in trial 1 and 0.8 to $12.3 \mathrm{~mm}$ in trial 2 (Table 1). Isolate Bot 01 was included in all six trials from the three experiments and had average lesion diameters ranging from 9.3 to $12.3 \mathrm{~mm}$. Five isolates (BT-3-b, C-4, CH-6-b, DD-9-b, and $\mathrm{S}-8-\mathrm{a})$ produced lesions $>10.5 \mathrm{~mm}$ in both trials, and three isolates (GO-2-b, S1-a, and UG-2) produced lesions with diameters $<6.0 \mathrm{~mm}$ in both trials. Ten isolates of $B$. cinerea produced lesions ranging from 1.0 to $8.8 \mathrm{~mm}$ that were significantly smaller than Bot 01 both times they were tested (Table 1). Lesion diameters between the two trials differed by $5 \mathrm{~mm}$ or more for only 4 of the 28 isolates (CC-4-a, CN-2-b, DD-8-a, and UG-1).
R. glutinis PM4 significantly limited lesion development by Bot 01 in four of six trials (Table 1). Lesion diameters from Bot 01 combined with yeast ranged from 5.5 to $10.8 \mathrm{~mm}$. Lesion diameters from 16 of the other 28 isolates were significantly smaller in both trials when isolates were combined with $R$. glutinis PM4. Lesion sizes ranged from 0.2 to $10.3 \mathrm{~mm}$. Eight other isolates (B-9-a, C-4, CH-1, GG-2-b, GO-1-a, H-3a, PS-5-a, and S-8-a) produced smaller lesions in one trial when co-inoculated with the yeast. The remaining three isolates (BT-3-b, DD-8-a, and S-1-a) were not affected by the presence of the yeast (Table 1). Isolate BT-3-b produced relatively large lesions $(\geq 11.8 \mathrm{~mm})$ and isolate $\mathrm{S}-1$-a produced relatively small lesions $(\leq 3.1 \mathrm{~mm})$ either with or without the yeast present. The third isolate (DD-8-a) produced large lesions $(\geq 10.4 \mathrm{~mm})$ in one trial and small lesions $(\leq 1.4 \mathrm{~mm})$ in the second trial. A large difference in lesion sizes $(>5 \mathrm{~mm})$ between the two trials was observed for 6 of the 28 isolates combined with the yeast (B-9-a, CH-1, CH-6-b, DD-8-a, GO-1-a, and UG-1).

Seedling assay. Diameters of lesions caused by six isolates of $B$. cinerea, with or without yeast, on the cotyledons of geranium seedlings differed significantly in each of the three trials of this experiment (Table 2). When isolates were inoculated without yeast, diameters ranged from 1.5 to $16.4 \mathrm{~mm}$ (Table 2). In comparison, the same isolates produced lesions 0.8 to 12.3 $\mathrm{mm}$ in diameter on geranium leaf disks (Table 1). When isolates were inoculated with yeast, lesion diameters ranged from 0.0 to $11.9 \mathrm{~mm}$ on cotyledons (Table 2) and from 0.4 to $12.2 \mathrm{~mm}$ on leaf disks (Table 1). In general, these six isolates produced larger lesions, after a 72-h incubation period, on cotyledons than on leaf disks but performed similarly in both assays; average lesion diameters (overall

Table 1. Lesion diameter on geranium leaf disks produced by 29 isolates of Botrytis cinerea when inoculated with or without the yeast Rhodotorula glutinis PM4 in two trials of each of three experiments ${ }^{\mathrm{w}}$

\begin{tabular}{|c|c|c|c|c|c|c|}
\hline \multirow[b]{2}{*}{ Isolate of $B$. cinerea $^{y}$} & \multicolumn{2}{|c|}{ Trial 1} & \multicolumn{2}{|c|}{ Trial 2} & \multicolumn{2}{|c|}{ Overall mean $^{x}$} \\
\hline & No yeast & Yeast & No yeast & Yeast & No yeast & Yeast \\
\hline \multicolumn{7}{|l|}{ Experiment 1} \\
\hline Bot 01 & $9.7 \mathrm{a}$ & $10.8 \mathrm{a}$ & $12.3 \mathrm{a}$ & $9.7 \mathrm{~b}$ & 11.0 & 10.1 \\
\hline BT-3-b & $11.9 \mathrm{a}$ & $11.8 \mathrm{a}$ & $12.3 \mathrm{a}$ & $12.2 \mathrm{a}$ & 12.1 & 12.0 \\
\hline C-4 & $11.6 \mathrm{a}$ & $11.0 \mathrm{a}$ & $11.6 \mathrm{a}$ & $8.0 \mathrm{~b}$ & 11.6 & 9.5 \\
\hline DD-9-b & $11.5 \mathrm{a}$ & $5.7 \mathrm{~b}$ & $11.1 \mathrm{a}$ & $7.4 \mathrm{~b}$ & 11.3 & 6.6 \\
\hline $\mathrm{CH}-1$ & $11.5 \mathrm{a}$ & $10.3 \mathrm{a}$ & $9.9 \mathrm{a}$ & $1.4 \mathrm{~b}$ & 10.7 & 5.9 \\
\hline S-8-a & $10.6 \mathrm{a}$ & $9.6 \mathrm{a}$ & $12.2 \mathrm{a}$ & $8.9 \mathrm{~b}$ & 11.4 & 9.3 \\
\hline $\mathrm{CN}-2-\mathrm{b}$ & $10.2 \mathrm{a}$ & $2.1 \mathrm{~b}$ & $5.2 \mathrm{a}$ & $0.3 \mathrm{~b}$ & 7.7 & 1.2 \\
\hline CC-1-a & $6.3 \mathrm{a}$ & $0.1 \mathrm{~b}$ & $7.6 \mathrm{a}$ & $2.1 \mathrm{~b}$ & 7.0 & 1.1 \\
\hline GO-2-b & $5.8 \mathrm{a}$ & $4.3 \mathrm{a}$ & $4.2 \mathrm{a}$ & $1.6 \mathrm{~b}$ & 5.0 & 3.0 \\
\hline UG-1 & $5.0 \mathrm{a}$ & $0.3 \mathrm{~b}$ & $10.5 \mathrm{a}$ & $6.8 \mathrm{~b}$ & 7.8 & 3.6 \\
\hline Trial $P>\mathrm{F}(\mathrm{LSD})^{\mathrm{z}}$ & \multicolumn{2}{|c|}{$<0.0001(2.2)$} & \multicolumn{2}{|c|}{$<0.0001(2.1)$} & & \\
\hline \multicolumn{7}{|l|}{ Experiment 2} \\
\hline Bot 01 & $10.0 \mathrm{a}$ & $5.5 \mathrm{~b}$ & $10.6 \mathrm{a}$ & $6.7 \mathrm{~b}$ & 10.3 & 6.1 \\
\hline CH-6-b & $11.5 \mathrm{a}$ & $5.1 \mathrm{~b}$ & $12.0 \mathrm{a}$ & $10.3 \mathrm{~b}$ & 11.8 & 7.7 \\
\hline DD-8-a & $10.4 \mathrm{a}$ & $11.2 \mathrm{a}$ & $1.4 \mathrm{a}$ & $1.3 \mathrm{a}$ & 5.7 & 6.3 \\
\hline GG-2-b & $10.0 \mathrm{a}$ & $6.4 \mathrm{~b}$ & $6.6 \mathrm{a}$ & $6.1 \mathrm{a}$ & 8.3 & 6.3 \\
\hline A-8-a & $8.0 \mathrm{a}$ & $5.3 \mathrm{~b}$ & $3.9 \mathrm{a}$ & $1.2 \mathrm{~b}$ & 6.0 & 3.3 \\
\hline BT-2-a & $7.5 \mathrm{a}$ & $2.0 \mathrm{~b}$ & $8.8 \mathrm{a}$ & $6.4 \mathrm{~b}$ & 8.2 & 4.2 \\
\hline FL-2-b & $7.0 \mathrm{a}$ & $4.2 \mathrm{~b}$ & $9.4 \mathrm{a}$ & $4.6 \mathrm{~b}$ & 8.2 & 4.4 \\
\hline S-1-a & $3.1 \mathrm{a}$ & $1.6 \mathrm{a}$ & $0.8 \mathrm{a}$ & $0.4 \mathrm{a}$ & 2.0 & 1.0 \\
\hline UG-2 & $2.5 \mathrm{a}$ & $0.4 \mathrm{~b}$ & $1.0 \mathrm{a}$ & $0.6 \mathrm{a}$ & 1.8 & 0.5 \\
\hline PS-5-a & $2.0 \mathrm{a}$ & $0.0 \mathrm{~b}$ & $6.2 \mathrm{a}$ & $3.1 \mathrm{~b}$ & 4.1 & 1.6 \\
\hline Trial $P>\mathrm{F}(\mathrm{LSD})^{\mathrm{z}}$ & \multicolumn{2}{|c|}{$<0.0001(1.7)$} & \multicolumn{2}{|c|}{$<0.0001(1.2)$} & & \\
\hline \multicolumn{7}{|l|}{ Experiment 3} \\
\hline Bot 01 & $9.3 \mathrm{a}$ & $5.9 \mathrm{~b}$ & $11.0 \mathrm{a}$ & $9.3 \mathrm{a}$ & 10.2 & 7.6 \\
\hline PL-4-b & $11.8 \mathrm{a}$ & $8.2 \mathrm{~b}$ & $8.9 \mathrm{a}$ & $3.2 \mathrm{~b}$ & 10.4 & 5.7 \\
\hline PB-2-a & $10.4 \mathrm{a}$ & $7.8 \mathrm{~b}$ & $9.6 \mathrm{a}$ & $4.3 \mathrm{~b}$ & 10.0 & 6.1 \\
\hline BR-1 & $9.1 \mathrm{a}$ & $1.6 \mathrm{~b}$ & $8.9 \mathrm{a}$ & $3.3 \mathrm{~b}$ & 9.0 & 2.5 \\
\hline B-9-a & $8.8 \mathrm{a}$ & $9.0 \mathrm{a}$ & $8.6 \mathrm{a}$ & $1.4 \mathrm{~b}$ & 8.7 & 5.2 \\
\hline PP-1-a & $8.8 \mathrm{a}$ & $0.4 \mathrm{~b}$ & $6.6 \mathrm{a}$ & $0.2 \mathrm{~b}$ & 7.7 & 0.3 \\
\hline $\mathrm{H}-3-\mathrm{a}$ & $8.3 \mathrm{a}$ & $2.1 \mathrm{~b}$ & $8.0 \mathrm{a}$ & $6.0 \mathrm{a}$ & 8.2 & 4.1 \\
\hline H-4-b & $7.1 \mathrm{a}$ & $0.5 \mathrm{~b}$ & $7.2 \mathrm{a}$ & $0.3 \mathrm{~b}$ & 7.2 & 0.4 \\
\hline GO-1-a & $6.9 \mathrm{a}$ & $2.3 \mathrm{~b}$ & $8.8 \mathrm{a}$ & $8.3 \mathrm{a}$ & 7.9 & 5.3 \\
\hline PP-7-a & $6.4 \mathrm{a}$ & $2.3 \mathrm{~b}$ & $7.1 \mathrm{a}$ & $4.3 \mathrm{~b}$ & 6.8 & 3.3 \\
\hline CC-4-a & $4.2 \mathrm{a}$ & $0.3 \mathrm{~b}$ & $10.6 \mathrm{a}$ & $1.1 \mathrm{~b}$ & 7.4 & 0.7 \\
\hline Trial $P>F(\mathrm{LSD})^{\mathrm{z}}$ & \multicolumn{2}{|c|}{$<0.0001(2.0)$} & \multicolumn{2}{|c|}{$<0.0001(2.1)$} & & \\
\hline
\end{tabular}

${ }^{\text {w}}$ No yeast or yeast treatments for each isolate of $B$. cinerea followed by a different letter within a trial are significantly different.

${ }^{x}$ The overall mean of each treatment from both trials are shown for comparison purposes to the seedling assay in Table 2.

y $B$. cinerea isolates were tested in three groups with isolate Bot 01 included in each trial as a control. Treatments included each isolate alone $\left(1 \times 10^{5}\right.$ conidia $\left.\mathrm{ml}^{-1}\right)$ or with $R$. glutinis PM4 $\left(1 \times 10^{6}\right.$ cells ml$\left.{ }^{-1}\right)$. Lesion diameter on the leaf disks was measured $(\mathrm{mm})$ after $72 \mathrm{~h}$ at $21^{\circ} \mathrm{C}$ for three replicates of 15 disks per treatment.

${ }^{\mathrm{z}}$ Data were analyzed for each trial by one-way analysis of variance $(P=0.05)$ because there were significant trial-treatment interactions and $B$. cinerea isolate-yeast interactions in two-way analysis of variance were significant $(P=0.05)$. Least significant differences $(\mathrm{LSDs} ; P=0.05)$ were determined for all 12 treatments in each trial. 
means; with and without yeast; Tables 1 and 2) between the two assays were correlated significantly $(r=0.750, P=0.005)$. Lesion development by one isolate was particularly variable; lesion diameters produced by DD-8-a without yeast varied considerably both among trials on seedling cotyledons $(2.7,13.8$, and $1.5 \mathrm{~mm}$; Table 2 ) and between trials on leaf disks (1.4 and $10.4 \mathrm{~mm}$; Table 1). In two of the three trials on seedlings (Table 2), lesion diameters were significantly smaller in the presence of yeast for all six isolates of $B$. cinerea; in the third trial, addition of yeast resulted in significantly smaller lesions with four of the six isolates. For all $B$. cinerea isolates, the addition of yeast reduced the mean diameter lesion size (averaged over the three trials) compared with the isolates inoculated alone. Three of the isolates used in this experiment (BT-3-b, DD-8-a, and S-1-a) were not affected by the yeast on leaf disks (Table 1), but these three isolates, when combined with yeast on cotyledons, produced significantly smaller lesions when compared with isolates without yeast in at least two of three trials (Table 2).

Effect of vinclozolin on yeast biological control efficacy. Lesion development by 10 isolates of $B$. cinerea resistant to vinclozolin ranged from 2.9 to $11.4 \mathrm{~mm}$ when inoculated alone onto the geranium cotyledons (Table 3). Overall, lesion diameters were relatively consistent between trials; only isolate $\mathrm{CN}-2-\mathrm{b}$ produced lesions in the two trials that differed by greater than $5 \mathrm{~mm}$. Addition of vinclozolin at $50 \mu \mathrm{g}$ a.i. $\mathrm{ml}^{-1}$ had little effect on lesion development among the 10 isolates; lesions were smaller compared with those produced by the isolate alone for only three isolates (BR-1, UG-1, and $\mathrm{H}-3-\mathrm{a}$ )each in one trial. Addition of $R$. glutinis PM4 significantly reduced lesion development on seedling cotyledons by all 10 isolates of $B$. cinerea compared with $B$. cinerea alone in at least one of two trials and by five isolates in both trials; in trials where the yeast was effective, lesion diameters ranged from 0.2 to $7.8 \mathrm{~mm}$. Of 10 isolates, 7 produced lesions that were smaller in the presence of PM4 than in the presence of vinclozolin in at least one trial, and 5 isolates produced smaller lesions with PM4 in both trials (Table 3). Isolates GG-2-b, CC-1-a, and H-3-a produced le-

Table 2. Lesion diameter on geranium seedling cotyledons produced by six isolates of Botrytis cinerea when inoculated with or without the yeast Rhodotorula glutinis PM4 in three trials ${ }^{\mathrm{w}}$

\begin{tabular}{|c|c|c|c|c|c|c|c|c|}
\hline \multirow[b]{2}{*}{ Isolate ${ }^{y}$} & \multicolumn{2}{|c|}{ Trial 1} & \multicolumn{2}{|c|}{ Trial 2} & \multicolumn{2}{|c|}{ Trial 3} & \multicolumn{2}{|c|}{ Overall mean $^{x}$} \\
\hline & No yeast & Yeast & No yeast & Yeast & No yeast & Yeast & No yeast & Yeast \\
\hline BT-3-b & $13.2 \mathrm{a}$ & $6.0 \mathrm{~b}$ & $16.4 \mathrm{a}$ & $11.8 \mathrm{~b}$ & $12.9 \mathrm{a}$ & $11.9 \mathrm{a}$ & 14.2 & 9.9 \\
\hline B-9-a & $13.6 \mathrm{a}$ & $0.5 \mathrm{~b}$ & $14.4 \mathrm{a}$ & $0.4 \mathrm{~b}$ & $12.1 \mathrm{a}$ & $1.6 \mathrm{~b}$ & 13.4 & 0.8 \\
\hline S-1-a & $9.6 \mathrm{a}$ & $0.6 \mathrm{~b}$ & $7.3 \mathrm{a}$ & $0.9 \mathrm{~b}$ & $3.0 \mathrm{a}$ & $0.2 \mathrm{~b}$ & 6.6 & 0.6 \\
\hline GO-2-b & $5.0 \mathrm{a}$ & $0.1 \mathrm{~b}$ & $12.0 \mathrm{a}$ & $6.3 \mathrm{~b}$ & $6.5 \mathrm{a}$ & $0.1 \mathrm{~b}$ & 7.8 & 2.2 \\
\hline UG-2 & $4.0 \mathrm{a}$ & $0.0 \mathrm{~b}$ & $2.9 \mathrm{a}$ & $0.0 \mathrm{~b}$ & $8.2 \mathrm{a}$ & $3.2 \mathrm{~b}$ & 5.0 & 1.1 \\
\hline DD-8-a & $2.7 \mathrm{a}$ & $0.0 \mathrm{~b}$ & $13.8 \mathrm{a}$ & $3.7 \mathrm{~b}$ & $1.5 \mathrm{a}$ & $0.0 \mathrm{a}$ & 6.0 & 1.2 \\
\hline Trial $P>F(\mathrm{LSD})^{\mathrm{z}}$ & \multicolumn{2}{|c|}{$<0.0001$} & \multicolumn{2}{|c|}{$<0.0001$} & \multicolumn{2}{|c|}{$<0.0001(2.3)$} & & \\
\hline
\end{tabular}

${ }^{\mathrm{w}}$ No yeast or yeast treatments for each isolate of $B$. cinerea followed by a different letter within a trial are significantly different.

$\mathrm{x}$ The overall mean of each treatment from the three trials are shown for comparison purposes to the leaf disk assay in Table 1.

y Isolates were selected that produced either large lesions ( $>8.5 \mathrm{~mm}$; BT-3-b, B-9-a, and DD-8-a) or smaller lesions ( $<6.0 \mathrm{~mm}$; GO-2-b, UG-2, and S-1-a) in at least one of two trials on leaf disks (Table 1$)$. Each $B$. cinerea isolate $\left(1 \times 10^{5}\right.$ conidia ml-1) with or without $R$. glutinis PM4 $\left(1 \times 10^{6}\right.$ cells ml $\left.{ }^{-1}\right)$ was inoculated onto both cotyledons of three replicate sets of 12 seedlings. Lesion diameters on cotyledons were measured after $72 \mathrm{~h}$ at $21^{\circ} \mathrm{C}$ in the dark.

${ }^{\mathrm{z}}$ Data were analyzed for each trial by one-way analysis of variance $(P=0.05)$ because there were significant trial-treatment interactions and $B$. cinerea isolate-yeast interactions in two-way analysis of variance were significant $(P=0.05)$. Least significant differences $(L S D s ; P=0.05)$ were determined for all 12 treatments in each trial.

Table 3. Lesion diameter produced by 10 isolates of Botrytis cinerea resistant to vinclozolin when inoculated alone or in combination with vinclozolin, Rhodotorula glutinis PM4, or both vinclozolin and $R$. glutinis PM4 on geranium cotyledons ${ }^{\mathrm{x}}$

\begin{tabular}{|c|c|c|c|c|c|c|c|}
\hline \multirow[b]{2}{*}{ Isolate of $B$. cinerea $^{\mathrm{Z}}$} & \multirow[b]{2}{*}{ Trial } & \multicolumn{4}{|c|}{ Treatments $^{\mathrm{y}}$} & \multirow[b]{2}{*}{$P$ value } & \multirow[b]{2}{*}{ LSD } \\
\hline & & B. cinerea alone & Vinclozolin & Yeast & Yeast and vinclozolin & & \\
\hline \multirow[t]{2}{*}{ FL-2-b } & 1 & $10.3 \mathrm{a}$ & $9.6 \mathrm{a}$ & $4.0 \mathrm{~b}$ & $1.0 \mathrm{c}$ & 0.003 & 2.6 \\
\hline & 2 & $7.5 \mathrm{a}$ & $7.3 \mathrm{a}$ & $2.7 \mathrm{~b}$ & $2.3 \mathrm{~b}$ & 0.046 & 4.4 \\
\hline \multirow[t]{2}{*}{ GG-2-b } & 1 & 10.5 & 11.5 & 9.7 & 8.3 & 0.431 & 4.6 \\
\hline & 2 & $9.7 \mathrm{a}$ & $8.4 \mathrm{ab}$ & $6.6 \mathrm{bc}$ & $5.5 \mathrm{c}$ & 0.017 & 2.3 \\
\hline \multirow[t]{2}{*}{ BR-1 } & 1 & $10.3 \mathrm{a}$ & $10.2 \mathrm{a}$ & $4.6 \mathrm{~b}$ & $1.6 \mathrm{c}$ & $<0.001$ & 1.1 \\
\hline & 2 & $9.5 \mathrm{a}$ & $5.6 \mathrm{~b}$ & $1.2 \mathrm{c}$ & $2.5 \mathrm{c}$ & 0.001 & 2.6 \\
\hline \multirow[t]{2}{*}{ BT-3-b } & 1 & $8.8 \mathrm{a}$ & $8.4 \mathrm{a}$ & $1.4 \mathrm{~b}$ & $0.4 \mathrm{~b}$ & $<0.001$ & 1.5 \\
\hline & 2 & $11.4 \mathrm{a}$ & $10.8 \mathrm{a}$ & $7.9 \mathrm{a}$ & $0.3 \mathrm{~b}$ & $<0.001$ & 3.5 \\
\hline \multirow[t]{2}{*}{ CH-6-b } & 1 & $8.6 \mathrm{a}$ & $6.5 \mathrm{a}$ & $2.0 \mathrm{~b}$ & $0.2 \mathrm{~b}$ & 0.002 & 3.3 \\
\hline & 2 & $9.9 \mathrm{a}$ & $11.3 \mathrm{a}$ & $8.2 \mathrm{a}$ & $2.6 \mathrm{~b}$ & 0.004 & 3.5 \\
\hline \multirow[t]{2}{*}{$\mathrm{CN}-2-\mathrm{b}$} & 1 & $11.1 \mathrm{a}$ & $10.6 \mathrm{a}$ & $7.8 \mathrm{~b}$ & $1.1 \mathrm{c}$ & $<0.001$ & 1.8 \\
\hline & 2 & $4.2 \mathrm{a}$ & $5.0 \mathrm{a}$ & $0.6 \mathrm{~b}$ & $0.0 \mathrm{~b}$ & 0.004 & 2.3 \\
\hline \multirow[t]{2}{*}{ UG-1 } & 1 & $7.6 \mathrm{a}$ & $3.9 \mathrm{~b}$ & $0.7 \mathrm{c}$ & $0.2 \mathrm{c}$ & $<0.001$ & 1.5 \\
\hline & 2 & $9.7 \mathrm{a}$ & $7.3 \mathrm{a}$ & $2.9 \mathrm{~b}$ & $0.2 \mathrm{~b}$ & $<0.001$ & 2.8 \\
\hline \multirow[t]{2}{*}{ S-1-a } & 1 & $5.7 \mathrm{a}$ & $6.1 \mathrm{a}$ & $0.6 \mathrm{~b}$ & $0.2 \mathrm{~b}$ & 0.003 & 2.7 \\
\hline & 2 & $2.9 \mathrm{a}$ & $4.1 \mathrm{a}$ & $0.2 \mathrm{~b}$ & $0.1 \mathrm{~b}$ & 0.015 & 2.4 \\
\hline \multirow[t]{2}{*}{ CC-1-a } & 1 & 4.2 & 3.2 & 2.1 & 0.0 & 0.153 & 3.9 \\
\hline & 2 & $5.1 \mathrm{a}$ & $2.3 \mathrm{ab}$ & $0.4 \mathrm{~b}$ & $0.1 \mathrm{~b}$ & 0.042 & 3.5 \\
\hline \multirow[t]{2}{*}{$\mathrm{H}-3-\mathrm{a}$} & 1 & 4.0 & 3.1 & 0.6 & 0.1 & 0.110 & 3.7 \\
\hline & 2 & $6.2 \mathrm{a}$ & $2.8 \mathrm{~b}$ & $0.3 \mathrm{~b}$ & $0.0 \mathrm{~b}$ & 0.008 & 3.1 \\
\hline
\end{tabular}

${ }^{\mathrm{x}}$ Data were analyzed for each trial by one-way analysis of variance $(P=0.05)$ because there were significant trial-treatment interactions and $B$. cinerea isolate-yeast interactions in two-way analysis of variance were significant $(P=0.05)$. Least significant differences $($ LSDs; $P=0.05)$ were determined for the four treatments for each $B$. cinerea isolate in each trial. Data followed by a different letter within a row are significantly different.

${ }^{\mathrm{y}}$ Treatments included each $B$. cinerea isolate $\left(1 \times 10^{5}\right.$ conidia $\left.\mathrm{ml}^{-1}\right)$ inoculated alone or in combination with vinclozolin $\left(50 \mu \mathrm{g}\right.$ a.i. $\left.\mathrm{ml}^{-1}\right)$, Rhodotorula glutinis PM4 $\left(1 \times 10^{6}\right.$ cells ml$\left.^{-1}\right)$, or both vinclozolin and $R$. glutinis PM4. A volume of $10 \mu$ of each treatment was placed onto both cotyledons of three replicate sets of 12 seedlings. Lesion diameters on cotyledons were measured after $72 \mathrm{~h}$ at $21^{\circ} \mathrm{C}$ in the dark.

z Vinclozolin sensitivity was determined by Yourman and Jeffers (27). 
sions of similar sizes in the presence of both PM4 and vinclozolin. In the presence of $R$. glutinis PM4, isolates BT-3-b, CH-6$\mathrm{b}$, and $\mathrm{CN}-2-\mathrm{b}$ produced lesions that differed in size by $>5 \mathrm{~mm}$ in the two trials. Yeast biocontrol efficacy was significantly improved by the addition of vinclozolin at $50 \mu \mathrm{g}$ a.i. $\mathrm{ml}^{-1}$ against $B$. cinerea isolates BR-1, BT-3-b, CH-6-b, CN-2-b, and FL-2$b$ in one of two trials. Lesion diameters from the 10 isolates of $B$. cinerea combined with yeast and vinclozolin were 2.6 $\mathrm{mm}$ or smaller in all trials, with the exception of GG-2-b $(8.3 \mathrm{~mm}$, trial $1 ; 5.5 \mathrm{~mm}$, trial 2). Vinclozolin did not negatively affect yeast biocontrol efficacy against any isolate of $B$. cinerea.

When the effect of vinclozolin at 0,5 , 50 , and $500 \mu \mathrm{g}$ a.i. $\mathrm{ml}^{-1}$ on lesion development was evaluated, there was no trial- treatment interaction; therefore, data from the two trials were combined for analysis. Addition of increasing rates of vinclozolin did not affect lesion development on geranium cotyledons by $B$. cinerea isolates FL2-b, BR-1, and GG-2-b based on regression lines with nonsignificant slopes (Fig. 1, dashed lines). Average lesion sizes with the different vinclozolin concentrations ranged from 10.7 to $11.4 \mathrm{~mm}$ for FL-2-b, from 11.7 to $12.5 \mathrm{~mm}$ for BR-1, and from 12.0 to $12.9 \mathrm{~mm}$ for GG-2-b. When vinclozolin was not present (i.e., $0 \mu \mathrm{g}$ a.i. $\mathrm{ml}^{-1}$ ), lesions were significantly smaller (ANOVA, $P=0.05$ ) in the presence of the yeast than when the yeast was not present for isolates BR-1 (5.4 versus $12.5 \mathrm{~mm}$, respectively) and GG-2-b (7.1 versus 12.8 $\mathrm{mm}$, respectively); yeast did not affect lesion development by isolate FL-2-b (9.3 versus $11.4 \mathrm{~mm}$, respectively). Vinclozolin concentration significantly affected yeast biocontrol efficacy against $B$. cinerea isolates FL-2-b and BR-1 but not against isolate GG-2-b (Fig. 1).

\section{DISCUSSION}

B. cinerea is a genetically diverse and highly variable plant pathogen, yet many studies use a single isolate or relatively few isolates to test the efficacy of potential biocontrol agents (e.g., 2,3,13,16-18,2628). In the present study, no obvious association was observed between the ability of the yeast $R$. glutinis PM4 to reduce disease and the relative aggressiveness of 29 isolates of $B$. cinerea. Effective and ineffective biocontrol was observed against isolates of $B$. cinerea producing a range of lesion sizes. The addition of vinclozolin to the biocontrol yeast, however, provided a highly effective and consistent level of disease management against the majority of vinclozolin-resistant isolates of $B$. cinerea. These results are consistent with those obtained by J. W. Buck when a single isolate of B. cinerea was used (3). The observation that some isolates of $B$. cinerea (e.g., BT-3-b or S-1-a) were not affected by the yeast in some trials highlights the need to use several different isolates when evaluating biocontrol efficacy in controlled experiments. This is in agreement with Chardonnet et al. (6), who concluded that biological and statistical variability in research could be affected by the selection of B. cinerea isolates.

Nutrient competition is assumed to be a primary mechanism of antagonism by yeasts against $B$. cinerea $(13,20)$. The ratio of yeast to B. cinerea (10:1) and the limited amount of nutrients $(25 \mathrm{mM}$ glucose and 20-fold dilute yeast nitrogen base) used in this and previous studies $(2,3)$ resulted in measurable disease on both geranium leaf disks and seedlings. This allowed for a comparison of the biocontrol efficacy by $R$. glutinis PM4 against a diversity of isolates of $B$. cinerea. Increasing either the ratio of yeast to $B$. cinerea or the
Fig. 1. Effect of vinclozolin concentration on diameter of lesions produced by three isolates of Botrytis cinerea (FL-2-b, BR-1, and GG-2-b) on geranium seedlings when inoculated without $(O)$ or with (-) the yeast Rhodotorula glutinis PM4. Data are individual means of three replications from two trials. Plotted lines are each B. cinerea isolate with vinclozolin (---) or with vinclozolin plus yeast (-). Vinclozolin concentrations were transformed ( $\log _{10} *$ [concentration]) for regression analysis but are presented as nontransformed concentrations for comparison purposes. $P$ values are the significance of the slope. For slopes that are significant, the regression equation and $P$ value are given. 
amount of glucose in the inoculation mixture virtually eliminated disease or biocontrol efficacy, respectively (2). For example, increasing the ratio of yeast to $B$. cinerea to $100: 1$ significantly reduced or eliminated lesion development on cotyledons by BT-3-b (1.8 mm), PB-2-a (no lesions), and B-9-a (no lesions) compared with the isolates inoculated without yeast (J. W. Buck, unpublished data).

Our working hypothesis was that biocontrol efficacy by the yeast would be less against more aggressive isolates (i.e., those that produced larger lesions over a fixed time interval) of $B$. cinerea than against less aggressive isolates. This did not occur because significant disease control was observed against 25 of 28 isolates on leaf disks and 14 isolates on cotyledons of seedlings in at least one trial. The three isolates that were not affected by the yeast on leaf disks included an aggressive isolate (BT-3-b) and two less aggressive isolates (DD-8-a and S-1-a). On cotyledons, the yeast did not affect three aggressive isolates (BT-3-b, CH-6-b, and GG-2-b,) one variable isolate (DD-8-a), and one less aggressive isolate (CC-1-a) in one of two or three trials.

A wide variation in aggressiveness was observed on geranium leaf disks and cotyledons among the isolates of $B$. cinerea used in this study. Of these isolates, 28 were a subsample of 325 isolates of $B$. cinerea collected from 35 commercial greenhouses growing ornamental crops in South Carolina (27). Genetic and phenotypic variability among isolates of $B$. cinerea is common. Significant genetic variability, as determined by random amplified polymorphic DNA analysis, was observed among 15 isolates of $B$. cinerea obtained from table grape, blueberry, apple, pear, and tomato in Chile (25), among 30 isolates of $B$. cinerea obtained over 12 months from a greenhouse containing roses in The Netherlands (21), and among 56 isolates of $B$. cinerea from greenhousegrown ornamental crops in South Carolina (28). Kerssies et al. (21) concluded that $B$. cinerea inoculum in greenhouses is ubiquitous and very heterogeneous. Any biocontrol organism used in greenhouses would have to be effective against a highly variable population of the pathogen; therefore, laboratory assays should address this by using multiple isolates or mixtures of isolates of $B$. cinerea.

Combining fungicides with biocontrol agents has improved the level of control of diseases on several fruit crops in both postharvest and field settings $(5,10,19)$. In a previous study (3), control of Botrytis blight on geranium seedlings was improved when several fungicides were combined with $R$. glutinis PM4 compared with the yeast alone (3). Addition of vinclozolin to $R$. glutinis PM4 provided a consistent level of disease control against a single vinclozolin-resistant isolate of $B$. cinerea
(3). In the current study, a relatively dilute concentration of vinclozolin $\left(50 \mu \mathrm{g}\right.$ a.i. $\mathrm{ml}^{-1}$ $=$ approximately $0.1 \times$ the label rate) $\mathrm{did}$ not negatively affect biocontrol efficacy against any of the 10 isolates of $B$. cinerea tested and significantly improved biocontrol efficacy against 5 of the isolates in at least one of two trials. The linear relationship between vinclozolin concentration and biocontrol efficacy against $B$. cinerea FL-2-b and BR-1 suggests that higher concentrations of this fungicide (i.e., 500 $\mu \mathrm{g}$ a.i. $\mathrm{ml}^{-1}$ ) would have a broader application in yeast biocontrol studies.

In general, isolates of $B$. cinerea were more aggressive, producing larger lesions during the same incubation period on cotyledons attached to actively growing geranium seedlings than on disks cut from approximately 12-week-old geranium leaves of the same cultivar. Age of geranium leaves is a key factor that affects infection by conidia of $B$. cinerea (24). Sirjusingh et al. (24) observed that 1-weekold leaves and mature to senescent leaves of geranium ( 8 to 10 weeks old) were highly receptive to infection and that expanding leaves (4 weeks old) were less receptive to infection by conidia of $B$. cinerea, presumably due to changes in cuticle thickness, tissue physiology, and other factors. A comparison of mature leaves to cotyledons was not done in their study. The larger lesions on cotyledons observed in the present study could be due to less fully developed physical barriers (e.g., thinner cuticular waxes) to fungal infection on cotyledons compared with the true leaves. An unexpected result was that yeast biocontrol efficacy also was greater (resulting in smaller lesions) on cotyledons than on leaf disks. For example, an aggressive isolate (BT-3-b) and a less aggressive isolate $(\mathrm{S}-1-\mathrm{a})$ were not affected by the presence of the yeast on leaf disks in two trials but were significantly affected by the yeast on cotyledons (i.e., smaller lesions were produced) in several trials. It is unclear why this happened.

In conclusion, the yeast $R$. glutinis PM4 continues to exhibit potential as an effective biocontrol agent against the ubiquitous pathogen $B$. cinerea on geranium. Biocontrol efficacy was observed against a diverse population of isolates of this pathogen that varied in aggressiveness as well as fungicide sensitivity. However, we observed poor biocontrol activity by $R$. glutinis PM4 against some isolates of $B$. cinerea; therefore, caution must be exercised when selecting isolates for biocontrol research to ensure a wide representation of the fungus population being targeted. Both geranium leaf disks and cotyledons on geranium seedlings provided viable and comparable assay systems for studying biocontrol efficacy; although biocontrol activity was greater on cotyledons. Combining dilute concentrations of vinclozolin with $R$. glutinis PM4 resulted in enhanced and more consistent disease management than with the yeast alone-even against isolates of $B$. cinerea resistant to this fungicide.

\section{ACKNOWLEDGMENTS}

We thank Goldsmith Seeds Inc. for providing geranium seed and R. Estes and D. Mueller for technical assistance.

\section{LITERATURE CITED}

1. Arras, G., Scherm, B., and Migheli, Q. 2002. Improving biocontrol activity of Pichia guillermondii against post-harvest decay of oranges in commercial packing-houses by reduced concentrations of fungicides. Biocontrol Sci. Technol. 12:547-553.

2. Buck, J. W. 2002. In vitro antagonism of $B o$ trytis cinerea by phylloplane yeasts. Can. J. Bot. 80:885-891.

3. Buck, J. W. 2004. Combinations of fungicides with phylloplane yeasts for improved control of Botrytis cinerea on geranium seedlings. Phytopathology 94:196-202.

4. Chand-Goyal, T., and Spotts, R. A. 1996. Postharvest biological control of blue mold of apple and brown rot of sweet cherry by natura saprophytic yeasts alone or in combination with low doses of fungicides. Biol. Control 6:253-259.

5. Chand-Goyal, T., and Spotts, R. A. 1997. Biological control of postharvest diseases of apple and pear under semi-commercial and commercial conditions using three saprophytic yeasts. Biol. Control 10:199-206.

6. Chardonnet, C. O., Sams, C. E., Trigiano, R. N., and Conway, W. S. 2000. Variability of three isolates of Botrytis cinerea affects the inhibitory effects of calcium on this fungus. Phytopathology 90:769-774.

7. Daughtrey, M. L., Wick, R. L., and Peterson, J. L. 1995. Compendium of Flowering Potted Plant Diseases. The American Phytopathological Society, St. Paul, MN.

8. Dik, A. J., Koning, G., and Köhl, J. 1999. Evaluation of microbial antagonists for biological control of Botrytis cinerea stem infection in cucumber and tomato. Eur. J. Plant Pathol. 105:115-122.

9. Droby, S., Cohen, L., Daus, A., Weiss, B., Horev, B., Chalutz, E., Hatz, H., Keren-Tzur, M., and Shachnai, A. 1998. Commercial testing of Aspire: a yeast preparation for the biological control of postharvest decay of citrus. Biol. Control 12:97-101.

10. Droby, S., Hofstein, R., Wilson, C. L., Wisniewski, M., Fridlender, B., Cohen, L., Weiss, B., Daus, A., Timar, D., and Chalutz, E. 1993. Pilot testing of Pichia guilliermondii: a biocontrol agent of postharvest diseases of citrus fruit. Biol. Control 3:47-52.

11. Droby, S., Lischinski, S., Cohen, L., Weiss, B., Daus, A., Chand-Goyal, T., Eckert, J. W., and Manulis, S. 1999. Characterization of an epiphytic yeast population of grapefruit capable of suppression of green mold decay caused by Penicillium digitatum. Biol. Control 16:27-34.

12. Elad, Y. 1996. Mechanisms involved in the biological control of Botrytis cinerea incited diseases. Eur. J. Plant Pathol. 102:719-732.

13. Elad, Y., Köhl, J., and Fokkema, N. J. 1994. Control of infection and sporulation of Botrytis cinerea on bean and tomato by saprophytic yeasts. Phytopathology 84:1193-1200.

14. El Ghaouth, A., Wilson, C. L., and Wisniewski, M. 1998. Ultrastructural and cytochemical aspects of the biological control of Botrytis cinerea by Candida saitoana in apple fruit. Phytopathology 88:282-291.

15. Epton, H. A. S., and Richmond, D. V. 1980. Formation, structure and germination of conidia. Pages 41-81 in: The Biology of Botrytis. J. R. Coley-Smith, V. Verhoeff, and W. R. Jarvis, eds. Academic Press, New York. 
16. Filonow, A. B., Vishniac, H. S., Anderson, J. A., and Janisiewicz, W. J. 1996. Biological control of Botrytis cinerea in apple by yeasts from various habitats and their putative mechanisms of antagonism. Biol. Control $7: 212-220$

17. Guetsky, R., Shtienberg, D., Elad, Y., Fisher, E., and Dinoor, A. 2002. Improving biological control by combining biocontrol agents each with several mechanisms of disease suppression. Phytopathology 92:976-985.

18. Guinebretiere, M. H., Nguyen-The, C., Morrison, N., and Nicot, P. 2000. Isolation and characterization of antagonists for the biocontrol of the postharvest wound pathogen Botrytis cinerea on strawberry fruits. J. Food Prot. 63:386394.

19. Harman, G. E., Latorre, B., Agosin, E., San Martin, R., Riegel, D. G., Nielsen, P. A., Tronsmo, A., and Pearson, R. C. 1996. Biological and integrated control of Botrytis bunch rot of grape using Trichoderma spp.
Biol. Control 7:259-266.

20. Janisiewicz, W. J., Tworkoski, T. J., and Sharer, C. 2000. Characterizing the mechanism of biological control of postharvest diseases on fruits with a simple method to study competition for nutrients. Phytopathology 90:11961200.

21. Kerssies, A., Bosker-van Zessen, A. I., Wagemakers, C. A. M., and van Kan, J. A. L. 1997. Variation in pathogenicity and DNA polymorphism among Botrytis cinerea isolates sampled inside and outside a glasshouse. Plant Dis. 81:781-786.

22. Qin, G. Z., Tian, S. P., Xu, Y., and Wan, Y. K. 2003. Enhancement of biocontrol efficacy of antagonistic yeasts by salicylic acid in sweet cherry fruit. Physiol. Mol. Plant Pathol. 62:147-154.

23. Qing, F., and Shiping, T. 2000. Postharvest biological control of Rhizopus rot of nectarine fruits by Pichia membranefaciens. Plant Dis. $84: 1212-1216$.
24. Sirjusingh, C., Sutton, J. C., and Tsujita, J. 1996. Effects of inoculum concentration and host age on infection of geranium by Botrytis cinerea. Plant Dis. 80:154-159.

25. Thompson, J. R., and Latorre, B. A. 1999 Characterization of Botrytis cinerea from table grapes in Chile using RAPD-PCR. Plant Dis. 83:1090-1094.

26. Wisniewski, M., Droby, S., Chalutz, E., and Eilam, Y. 1995. Effects of $\mathrm{Ca}^{2+}$ and $\mathrm{Mg}^{2+}$ on Botrytis cinerea and Penicillium expansum in vitro and on the biocontrol activity of Candida oleophila. Plant Pathol. 44:1016-1024.

27. Yourman, L. F., and Jeffers, S. N. 1999. Resistance to benzimidazole and dicarboximide fungicides in greenhouse isolates of Botrytis cinerea. Plant Dis. 83:569-575.

28. Yourman, L. F., Jeffers, S. N., and Dean, R. A 2001. Genetic analysis of isolates of Botrytis cinerea sensitive and resistant to benzimidazole and dicarboximide fungicides. Phytopathology 90:851-859. 